Pacific Journal of Mathematics

GENERATING ORIENTED GRAPHS BY MEANS OF TEAM 


\title{
GENERATING ORIENTED GRAPHS BY MEANS OF TEAM COMPARISONS
}

\author{
J. W. Moon AND L. Moser
}

Two teams $A$ and $B$ can be compared by matching each player in $A$ against each player in $B$. We say that $A>B$ if and only if the players of $A$ collectively win more games against players of $B$ than they lose. If there are $n$ teams $T_{1}, T_{2}, \cdots, T_{n}$, then the outcomes of the matches between the various teams may be represented by an oriented graph $H_{n}$ on $n$ nodes in which an arc goes from the $i$-th node to the $j$-th node if and only if $T_{i}>T_{j}$. It is shown that any oriented graph can be generated in this way, and that the minimum number of players necessary to generate any oriented graph $H_{n}$ is of the order of $n^{2} / \log n$.

If $A=\left\{a_{1}, a_{2}, \cdots, a_{r}\right\}$ and $B=\left\{b_{1}, b_{2}, \cdots, b_{s}\right\}$ are two nonempty finite sets of real numbers, we say $A>B$ if and only if the number of solutions of $a_{i}>b_{j}$ exceeds the number of solutions of $a_{i}<b_{j}$. We think of the sets $A$ and $B$ as teams of players. The numbers in the sets denote both the names and the strengths of the players; we assume the stronger player always wins in any game between two players. A match between the teams $A$ and $B$ consists of $r s$ individual games between the players of $A$ and $B$. The stronger team is the team whose players win a majority of the games. (We admit the possibility of draws, both between individual players and between teams.)

Let $N$ players $x_{1}, x_{2}, \cdots, x_{N}$ be split into $n$ teams $T_{1}, T_{2}, \cdots, T_{n}$ and suppose that every team plays against every other team. (We assume throughout that $n>1$.) The results of these matches may be represented by an oriented graph $H_{n}$ on $n$ nodes $t_{1}, t_{2}, \cdots, t_{n}$ in which an are goes from $t_{i}$ to $t_{j}$ if and only if $T_{i}>T_{j}$. For example, the teams $T_{1}=\{6,7,2\}, T_{2}=\{1,5,9\}$, and $T_{3}=\{8,3,4\}$ generate the graph $H_{3}$ shown in Figure 1 .

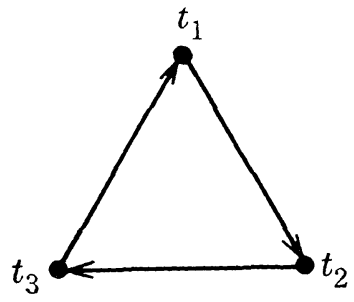

Figure 1.

In $\S 2$ we show that any oriented graph can be generated by 
means of team comparisons and in $\S 3$ we consider the problem of determining the minimum number of players necessary to generate any oriented graph $H_{n}$.

2. Generating arbitrary oriented graphs. If the teams

$$
T_{1}, T_{2}, \cdots, T_{n}
$$

generate the oriented graph $H_{n}$ let $\alpha(i, j)$ denote the net score of $T_{i}$ against $T_{j}$, i.e., the number of games won minus the number of games lost by players of $T_{i}$ against players of $T_{j}$. Let $w$ and $s$ denote the strengths of the weakest and strongest players on the $n$ teams and choose numbers $w_{1}, w_{2}, s_{1}$ and $s_{2}$ such that $w_{1}=w_{2}<w$ and $s_{1}>s_{2}>s$. If we add two players of sirength $s_{1}$ and $w_{1}$ to $T_{i}$ and two players of strength $s_{2}$ and $w_{2}$ to $T_{j}$, it is readily verified that the only affect this has upon the net scores between the different teams is to increase $\alpha(i, j)$ by one.

This process can of course be repeated. It follows that if the net scores between the teams are prescribed in advance, and if their sum is $\beta$, then no more than $n+4 \beta$ players are necessary to realize these scores, since we may assume that initially there are $n$ players of equal strength, one on each team. (We remark that although the net scores can be prescribed arbitrarily, the win-loss ratios for the matches between the various teams cannot all be prescribed arbitrarily in general; this follows from results of Steinhaus and Trybula [4] and Usiskin [5].) In particular, therefore, any oriented graph $H_{n}$ can be generated by $n+4\left(\begin{array}{l}n \\ 2\end{array}\right)=2 n^{2}-n$, or fewer, players. A simple induction argument, using a refinement of this construction, shows that no more than $n^{2}+3 n-11$ players are necessary to generate any oriented graph $H_{n}$ if $n \geqq 3$. Our main result gives a sharper bound (for large $n)$ that, in a sense, is best possible.

\section{Main result.}

THEOREM. If $\lambda(n)$ denotes the least integer $N$ such that the number of players needed to generate any oriented graph $H_{n}$ is at most $N$, then there exist positive constants $c_{1}$ and $c_{2}$ such that

$$
\frac{c_{1} n^{2}}{\log n}<\lambda(n)<\frac{c_{2} n^{2}}{\log n}
$$

Proof. If $N$ players can generate the graph $H_{n}$, then the strengths of the $N$ players can be taken from the integers $1,2, \cdots, N$. (Some of the players may have the same strength.) The number of ways of forming $n$ teams from not more than $N$ players, whose strengths are taken from the integers $1,2, \cdots, N$, is certainly not more than 
$(2 n)^{N}$. There are $3^{\left(\begin{array}{c}n \\ 2\end{array}\right)}$ oriented graphs $H_{n}$. Consequently, if $N$, or fewer, players suffice to generate every oriented graph $H_{n}$, it must be that

$$
(2 n)^{N} \geqq 3^{\left(\begin{array}{c}
n \\
2
\end{array}\right)},
$$

or

$$
N \geqq \frac{\log 3}{2} \frac{n(n-1)}{\log (2 n)},
$$

since each allocation of players determines at most one graph.

This implies the lower bound of the theorem; the upper bound will follow from three lemmas.

Consider a special oriented graph that consists of two disjoint sets of nodes, $A$ and $B$, such that an arc goes from each node of $A$ to each node of $B$; any oriented graph with $n$ nodes that can be expressed as the union of disjoint special graphs will be called a bilevel graph $B_{n}$. (We admit the possibility that one of the node-sets of one of the special graphs composing $B_{n}$ is empty.) The structure of a typical bilevel graph, composed of four special graphs, is indicated in Figure 2.
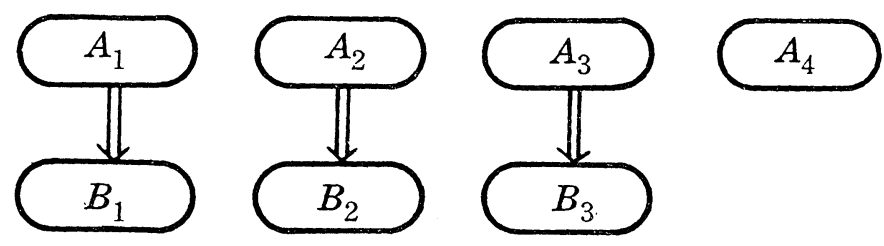

Figure 2.

Lemma 1. Any bilevel graph $B_{n}$ can be generated by $2 n$ players, two on a team.

Proof. We illustrate the proof on the bilevel graph depicted in Figure 2. Associate each node in the various node-sets with the team indicated in the following list.

$$
\begin{aligned}
& A_{1}:(1,20) \quad A_{2}:(2,18) \quad A_{3}:(3,16) \quad A_{4}:(4,14) \\
& B_{1}:(1,19) \quad B_{2}:(2,17) B_{3}:(3,15)
\end{aligned}
$$

One can verify directly that this allocation of players, two on each team, will generate the bilevel graph in Figure 2. An analogous construction will generate any bilevel graph $B_{n}$. (We remark that it is easy to modify this construction to show that the lemma remains true even if it is insisted that no two different players have the same strength.) 
LEMMA 2. If the oriented graph $H_{n}$ can be expressed as the union of $l$ arc-disjoint bilevel graphs $B^{(1)}, B^{(2)}, \cdots, B^{(l)}$, all of which have the same $n$ nodes, then $H_{n}$ can be generated by $2 l n$ players, $2 l$ on a team.

Proof. There exist teams $R_{i k}$ of two players each, according to Lemma 1 , such that the teams $R_{i k}, i=1,2, \cdots, n$, generate the graphs $B^{(k)}$, for $k=1,2, \cdots, l$. We may assume that every player on any team $R_{j k}$ is stronger than every player on any team $R_{i h}$, for $1 \leqq h<k \leqq l$. (This property can be ensured by adding, if necessary, a suitable constant $c_{k}$ to the strength of every player on the teams $R_{i k}, k=1,2, \cdots, l$.) The teams

$$
T_{i}=\bigcup_{k=1}^{l} R_{i k}, \quad i=1,2, \cdots, n
$$

each have $2 l$ players and it is not difficult to see that they generate the oriented graph $H_{n}$.

The following nontrivial result was proved by Erdös and Moser [1].

LEMMA 3. There exists a (large) constant $c$ such that any oriented graph $H_{n}$ can be expressed as the union of $l$ arc-disjoint bilevel graphs, all of which have the same $n$ nodes, where

$$
l<\frac{c n}{\log n}
$$

This suffices to complete the proof of the theorem.

4. Remarks. There are certain curious aspects of this mode of comparison arising from its lack of transitivity. In the example given in $\S 1$, the teams $T_{1}, T_{2}$ and $T_{3}$ were such that $T_{1}>T_{2}$ and $T_{2}>T_{3}$. One might expect that $T_{1} \cup T_{2}>T_{2} \cup T_{3}$, and this is indeed the case. However, since $T_{1}<T_{3}$, one might equally well expect that $T_{1} \cup T_{2}<T_{2} \cup T_{3}$, and this is false.

The following example is rerhaps more striking. If $A=\{2,3,10\}$ and $B=\{1,8,9\}$ then $A>B$ by 5 wins to 4 . If $A_{1}=A \cup\{5\}$ and $B_{1}=B \cup\{4\}$, then the teams $A_{1}$ and $B_{1}$ are tied with 8 wins each. If $A_{2}=A_{1} \cup\{7\}$ and $B_{2}=B_{1} \cup\{6\}$ then $B_{2}>A_{2}$ by 13 wins to 12 . Notice that at each stage we added the stronger player to the team that was the stronger originally, yet the net affect was to reverse the relative strengths of the two teams. This process can be continued. If $A_{3}=A_{2} \cup\{12\}$ and $B_{3}=B_{2} \cup\{11\}$, then $A_{3}$ and $B_{3}$ are tied 
with 18 wins each. Finally, if $A_{4}=A_{3} \cup\{14\}$ and $B_{4}=B_{3} \cup\{13\}$, then $A_{4}>B_{4}$ by 25 wins to 24 .

We mention briefly another method of comparing two teams $A$ and $B$ of $n$ players each. The players of $A$ are lined up in some fixed order and paired off against all $n$ ! orderings of the players of $B$. The team that wins a majority of the $n$ ! matches will be declared winner. The six matches between $T_{1}$ and $T_{2}$ of $\S 1$ are as follows:

\begin{tabular}{llll} 
& 6, & 7, & 2 \\
\cline { 2 - 3 } 1. & 1, & 5, & 9 \\
2. & 1, & 9, & 5 \\
3. & 5, & 1, & 9 \\
4. & 5, & 9, & 1 \\
5. & 9, & 1, & 5 \\
6. & 9, & 5, & 1
\end{tabular}

The team $T_{1}=\{6,7,2\}$ wins matches $1,3,4,6$ and loses matches 2 and 5 . Thus $T_{1}>T_{2}$ by 4 wins to 2 . Similarly we find that

$$
T_{2}>T_{3} \text { and } T_{3}>T_{1}
$$

by 4 wins to 2 also.

We remark in closing that other related ways of generating oriented graphs have been discussed by McGarvey [3], and Erdös and Moser [1].

\section{REFERENCES}

1. P. Erdös and L. Moser, On the representation of directed graphs as unions of orderings, Publi. Math. Inst. Hung. Acad. Sci. 9 (1964), 125-132.

2. D. C. McGarvey, A theorem on the construction of voting paradoxes, Econometrica 21 (1953), 608-610.

3. R. Stearns, The voting problem, Amer. Math. Monthly 66 (1959), 761-763.

4. H. Steinhaus and S. Trybula, On a paradox in applied probabilities, Bull. Acad. Polon. Sci. Sér. Sci. Math. Astronom. Phys. 7 (1959), 67-69.

5. Z. Usiskin, Max-min probabilities in the voting paradox, Ann. Math. Statist. 35 (1964), 857-862.

Received July 25, 1966.

UNIVERSITY OF ALBERTA 



\section{PACIFIC JOURNAL OF MATHEMATICS}

\section{EDITORS}

\section{H. SAMELSON}

Stanford University

Stanford, California

\author{
J. P. JANS \\ University of Washington \\ Seattle, Washington 98105
}

\section{J. DuGUNDJI}

University of Southern California

Los Angeles, California 90007

RichaRd ARENS

University of California

Los Angeles, California 90024

\section{ASSOCIATE EDITORS}

E. F. BECKENBACH
B. H. NeUManN

F. WOLF

K. YOSIDA

\section{SUPPORTING INSTITUTIONS}

UNIVERSITY OF BRITISH COLUMBIA

CALIFORNIA INSTITUTE OF TECHNOLOGY

UNIVERSITY OF CALIFORNIA

MONTANA STATE UNIVERSITY

UNIVERSITY OF NEVADA

NEW MEXICO STATE UNIVERSITY

OREGON STATE UNIVERSITY

UNIVERSITY OF OREGON

OSAKA UNIVERSITY

UNIVERSITY OF SOUTHERN CALIFORNIA
STANFORD UNIVERSITY

UNIVERSITY OF TOKYO

UNIVERSITY OF UTAH

WASHINGTON STATE UNIVERSITY

UNIVERSITY OF WASHINGTON

AMERICAN MATHEMATICAL SOCIETY

CHEVRON RESEARCH CORPORATION

TRW SYSTEMS

NAVAL ORDNANCE TEST STATION

Mathematical papers intended for publication in the Pacific Journal of Mathematics should be typewritten (double spaced). The first paragraph or two must be capable of being used separately as a synopsis of the entire paper. It should not contain references to the bibliography. Manuscripts may be sent to any one of the four editors. All other communications to the editors should be addressed to the managing editor, Richard Arens at the University of California, Los Angeles, California 90024.

50 reprints per author of each article are furnished free of charge; additional copies may be obtained at cost in multiples of 50 .

The Pacific Journal of Mathematics is published monthly. Effective with Volume 16 the price per volume ( 3 numbers) is $\$ 8.00$; single issues, $\$ 3.00$. Special price for current issues to individual faculty members of supporting institutions and to individual members of the American Mathematical Society: $\$ 4.00$ per volume; single issues $\$ 1.50$. Back numbers are available.

Subscriptions, orders for back numbers, and changes of address should be sent to Pacific Journal of Mathematics, 103 Highland Boulevard, Berkeley 8, California.

Printed at Kokusai Bunken Insatsusha (International Academic Printing Co., Ltd.), No. 6, 2-chome, Fujimi-cho, Chiyoda-ku, Tokyo, Japan.

PUBLISHED BY PACIFIC JOURNAL OF MATHEMATICS, A NON-PROFIT CORPORATION

The Supporting Institutions listed above contribute to the cost of publication of this Journal, but they are not owners or publishers and have no responsibility for its content or policies. 


\section{Pacific Journal of Mathematics}

\section{Vol. 21, No. $3 \quad$ BadMonth, 1967}

Richard Allen Askey, A transplantation theorem for Jacobi coefficients . . . 393

Raymond Balbes, Projective and injective distributive lattices .......... 405

Raymond Balbes and Alfred Horn, Order sums of distributive lattices . . . . 421

Donald Charles Benson, Nonconstant locally recurrent functions ........ 437

Allen Richard Bernstein, Invariant subspaces of polynomially compact operators on Banach space ............................... 445

Robert F. Brown, Fixed points and fibre ................... 465

David Geoffrey Cantor, On the Stone-Weierstrass approximation theorem for valued fields ................................ 473

James Walton England, Stability in topological dynamics .............. 479

Alessandro Figà-Talamanca and Daniel Rider, A theorem on random

Fourier series on noncommutative groups.................. 487

Sav Roman Harasymiv, A note of dilations in $L^{p} \ldots \ldots \ldots \ldots \ldots \ldots . \ldots 493$

J. G. Kalbfleisch, A uniqueness theorem for edge-chromatic graphs ....... 503

Richard Paul Kelisky and Theodore Joseph Rivlin, Iterates of Bernstein polynomials .................................... 511

D. G. Larman, On the union of two starshaped sets ............... 521

Henry B. Mann, Josephine Mitchell and Lowell Schoenfeld, Properties of differential forms in $n$ real variables ...................... 525

John W. Moon and Leo Moser, Generating oriented graphs by means of team comparisons .

Veikko Nevanlinna, A refinement of Selberg's asymptotic equation ...

Ulrich Oberst, Relative satellites and derived functors of functors with additive domain ..............................

John Vincent Ryff, On Muirhead's theorem...............

Carroll O. Wilde and Klaus G. Witz, Invariant means and the Stone-Čech compactification 